\title{
The interbank market risk premium, central bank interventions, and measures of market liquidity
}

\author{
Annika Alexius; Helene Birenstam† and Johanna Eklund ${ }^{\ddagger}$
}

February 4, 2014

\begin{abstract}
When the interbank market risk premium soared during the financial crisis, it created a wedge between interest rates actually paid by private agents and the rapidly falling policy rates. Many central banks attempted to improve the situation by supplying liquidity to the domestic interbank market. This paper studies the Swedish interbank market risk premium using a unique data set on traded volume between banks and between banks and the Riksbank. We find that the main determinants of the Swedish interbank premium are international variables, such as US and EURO area risk premia. International exchange rate volatility and the EURO/USD deviations from CIP also matters, while standard mesures of domestic market liquidity and domestic credit risk have insignificant effects. Our measure of actual turnover in the interbank market is however associated with a significant reduction of the interbank market risk premium, as are credit provisions by the central bank.
\end{abstract}

Keywords: Interbank market risk premium, liquidity risk, credit risk, credit provisions.

JEL classifications: F31, F41.

\footnotetext{
*Annika Alexius, Department of Economics, Stockholm University, 10691 Stockholm, Sweden. E-mail: annika.alexius@ne.su.se.

${ }^{\dagger}$ Helene Birenstam, Department of Statistics, Stockholm University. E-mail: helene.birenstam@stat.su.se.

${ }^{\ddagger}$ Johanna Eklund, Financial Stability Department, Sveriges Riksbank. E-mail: johanna.eklund@riksbank.se.
} 


\section{Introduction}

The interbank market received relatively little academic attention until the financial crisis in 2007-09, when the risk premium in this particular market sky rocketed. The resulting wedge between central bank policy interest rates and the interest rates paid by consumers and investors turned into a major concern during the recession, partly because this hampered the expansionary effects of monetary policy. For instance, the Federal Funds Rate was lowered by 5.25 percent between September 2007 and December 2008, but bank lending rates only fell by 1.1 percent during the same period. Instead, the interbank market risk premium increased from a stable level around 7 basis points to a maximum of 360 basis points or 3.60 percent in October 2008 . Since this episode, both policy institutions and academic researchers have devoted considerable attention to how the interbank market risk premium is determined and what central banks can do to affect it. The relative importance of illiquidity versus credit risk (and/or other risks) is important not only from an academic point of view but also because different policy measures are called for depending on which factors that cause movements in the interbank market risk premium. Central banks have a variety of tools at their disposal for improving market liquidity, but these interventions are only effective to the extent that the interbank market risk premium is actually driven by illiquidity rather than by other factors.

This paper utilizes a unique data set on the transaction volume in the Swedish interbank market to investigate how liquidity, credit risk, Riksbank interventions, and other factors affect the interbank market risk premium in Sweden. Our data set differs from transaction volume data from e-Mid and target2 used by e.g. Michaud and Upper (2008), and Heijmans et al 
(2010) in that the Riksbank collects all transactions in the Swedish interbank market, while e-Mid covers a small (less than 20 percent) and falling fraction of the EURO interbank market. We compare interbank market liquidity as measured by transaction volume data from the Riksbank to the standard liquidity measure in this literature, which is the interest rate spread between covered and uncoved sovereign bonds (Schwartz, 2010, Valenzuela, 2010, and others).

Since 2008, the empirical literature on the interbank market risk premium has burgeoned. Different studies using different measures of liquidity, credit risk, and various other variables such as risk aversion have reached different conclusions concerning the importance of these factors to movements in the risk premium. Taylor and Williams (2009) and others find that the interbank market risk premium is mainly driven by credit risk. Their measure of liquidity does not have significant effects. Using different measures of both market liquidity and credit risk, Schwartz (2010) concludes that liquidity risk is the more important factor. Fukuda (2011) studies interbank rate rates across currency denominations to identify the different effects (both the Tokyo Interbank Offered Rate (TIBOR) and the London Interbank Offered Rate (LIBOR) are quoted in Yen as well as in US dollars). He finds that counter party credit risk in a specific country affects the TIBOR-LIBOR interest rate differential across currency denominations, while liquidity conditions appear to be currency specific and affect dollar denominated interest rates (TIBOR and LIBOR) differently from corresponding interest rates denominated in Yen. Michaud and Upper (2008) document a long run relationship between credit risk and the interbank market risk premium in time series data, but find only insignificant effects on day to day movements in interbank spreads. They also investigate a cross section of LIBOR inter- 
bank rates for different banks and find that credit default swap prices for the borrowing banks are statistically unrelated to the risk premia paid by these banks. According to Angelini et al. (2011), two thirds of the soaring interbank spread during the 2008 financial crisis was due to increased risk aversion rather than credit risk or illiquidity.

The empirical results concerning the relative importance of market liquidity for the interbank market risk premium appear to be systematically related to the proxies used to capture the different effects. Credit risk is typically measured using data on bank credit default spreads (as in Taylor and Williams (2009), Fukuda (2011), Michaud and Upper (2008)). The main exception is Schwartz (2010), who calculates the spread between interbank rates paid by banks with high versus low credit ratings. Since the probability of default can be calculated using CDS prices, several studies calculate rather than estimate the effect of counterpart credit risk on the interbank market risk premium (Bank of England 2007, Poskitt 2011).

Capturing liquidity in an OTC (over the counter) market such as the interbank market turns out to be more difficult. Data on the measures of liquidity frequently used in studies of stock markets (such as bid-ask spreads or traded volume) are typically unavailable in case of the interbank market since it is dominated by bilateral transaction and detailed information about these is rarely collected. Taylor and Williams (2009), Fukuda (2011) and others estimate the impact of liquidity provisions by central banks and conclude that liquidity conditions affect the interbank market risk premium iff these liquidity provisions have significant effects. However, liquidity provided by central banks is not necessarily a perfect substitute for market liquidity. Schwartz (2010) uses the spread between bonds with (ideally) the same expected cash flows but different liquidity characteristics to capture 
the liquidity premium. Similarly, Valenzuela (2010) measures liquidity risk as the spread between US sovereign bonds and AAA bonds of international organizations. As discussed in Section 2, this strategy identifies an asset specific liquidity premium on covered bonds. While this premium may well be empirically correlated with the interbank market liquidity premium, these two premia are in theory determined by different factors.

The single most important variable behind movements in the Swedish interbank market risk premium turns out to be the US interbank market risk premium, followed by international exchange rate volatility and the deviations from covered interest rate parity between the EURO and the USD. As discussed by Baba and Packer (2009), the latter variable can be assumed to capture the shortage of US dollar credit in Europe during the financial crisis. Somewhat surprisingly, we find that domestic credit risk, measured as the average credit default spread for major Swedish banks, does not affect the interbank market risk premium significantly once we control for international variables. This implies that the strategy to first calculate the theoretical credit risk premium from CDS data, deduct the resulting credit premium from the actual interbank market risk premium and then either conclude that the remaining part of the risk premium is due to liquidity risk (as in Bank of England, 2007) or estimate the effects of liquidity and other variables on the remaining part of the risk premium (as in Poskitt, 2011) may be empirically questionable.

Higher domestic liquidity as measured by interbank market transaction volume is associtated with a significantly lower interbank market risk premium. Liquidity measured as the yield spread between covered and sovereign bonds is barely correlated with interbank market traded volume at all, and the bond spread displays high correlations with measures of credit 
risk and stock market volatility. Credit provisions by the Riksbank are also associated with a significant reduction of the risk premium. The size of this effect does not differ significantly from the effect of trade between banks. Hence liquidity provided by the Riksbank could be a substitute for market liquidity. As shown in section 4.2, the results concerning the effects of the Riksbank interventions are somewhat sensitive to the set of control variables used.

\section{Measuring interbank market liquidity}

As a general notion, liquidity is defined as the ease with which assets are traded. An illiquid asset is more difficult to sell than a liquid asset. Similarly, it is more difficult to buy and sell assets on an illiquid market than on a liquid market. This is often modeled as an exogenous transaction cost that may vary over time and/or between different assets and markets. The most common empirical counterpart is bid-ask spreads, data on which is typically unavailable in the case of over the counter (OTC) markets such as the interbank market.

Rather than just assuming an exogenous transaction cost to model illiquidity, this cost can be derived endogenously through several different mechanisms. In models with asymmetric information and adverse selection, the transaction cost depends on the probability of dealing with an informed trader and on how much additional information she has. Such models are developed by Glosten and Milgrom (1985) and Kyle (1985). The quantitative importance of this mechanism can be captured by measuring the impact of an additional net order flow on market prices. The more information that is revealed by an additional unit of trade, the more it affects the equilibrium 
price and the higher is the transaction cost due to asymmetric information. A common empirical proxy is the average change in market price per unit of trade (Korajdsyk and Sadka, 2008). More complex measures of the effect of asymmetric information on transaction costs can also be constructed, such as the difference in bid-ask spread between small orders and large orders divided by the corresponding difference in order size (Goyenko et al., 2009).

A second strand of the theoretical literature on liquidity premia as an endogenously derived transaction cost focuses the inventory risk of market makers (Amihud and Mendelson, 1980). It is more risky and hence more costly to hold an asset before being able to re-sell it if asset returns are volatile, traded volume or turnover is low and/or volatile, the more of this asset the market maker already holds, and the less diversifiable these risks are. The theoretical concept of liquidity here centers around "the value of immediacy", i.e. the willingness to pay for immediate trade with a market maker rather than delaying the transaction while finding a buyer. As above, empirical measures capture how much the market price is temporarily depressed by e.g. an unexpected sell order. A standard proxy is again the average change in market price per unit of trade.

The third mechanism for creating endogenous transaction costs is particularly relevant to OTC markets, such as the interbank market. Search frictions and bilateral bargaining can cause differences in return also between assets with identical expected cash flows if these assets have different liquidity characteristics. The theoretical illiquidity concept in these model corresponds to the time it takes before an asset can be sold. Assets that are traded more frequently are associated with lower search costs and hence carry a lower liquidity premium. The theoretical model that has the closest connection to the empirical literature on liquidity premia in the interbank 
market is Vayanos and Weill (2008), who show how bonds with identical cash flows but different liquidity characteristics can trade at different prices. ${ }^{1}$ Securities with larger float (supply) or higher trading volume have less severe search problems and correspondingly lower liquidity premia in equilibrium. Observable related proxies of market liquidity are relative asset supplies, traded volumes, or the return differential between assets with the same cash flow but different liquidity characteristics (such as the yield spread between sovereign and covered bonds used to identify the liquidity premium in the interbank market in Schwartz, 2010, Valenzuela, 2010, and Dubecq et al., 2013).

Given that liquidity is modelled as a transaction cost (exogenous or endogenous), the next question is how it is priced in equilibrium. The theoretical literature contains several points about the pricing of liquidity that are relevant to the choice of empirical proxies for liquidity in the interbank market. For instance, asset specific liquidity and market liquidity are two different concepts. Hence, the market liquidity premium is not necessarily captured by measures of asset specific liquidity premia, which is what the Schwartz (2010) and Valenzuela (2010) strategy implies. In standard models, deterministic differences in transaction costs (liquidity) between assets only commands a negligible (second order) premium in equilibrium because optimizing investors are able to allocate their portfolios to trade their liquid assets while holding their illiquid assets (Constantinides 1986, Heaton and Lucas, 1996). In contrast, market wide liquidity shocks can result in a

\footnotetext{
${ }^{1}$ Vayanos and Wang (2007) develop a search-based model of asset pricing with risk neutral investors. Duffie, Garleanu and Pedersen (2005) assume that there is a market maker, while Duffie, Garleanu and Pedersen (2007) assume that investors meet randomly and bargain biletarally.
} 
substantial liquidity premium, especially if the shocks are permanent rather than transitory (Acharya and Pedersen, 2005).

There is also a conceptual difference between the amount of liquidity (as measured e.g. by the volume of trade on a specific market) and the equilibrium price of liquidity (as measured e.g. by yield differences between two otherwise identical assets with different liquidity characteristics). In Acharya and Pedersen (2005), the asset specific liquidity premium is higher for assets whose illiquidity covaries positively with market illiquidity and market return. ${ }^{2}$ The reason is that investors pay a premium for assets that are liquid in times of low market return and vice versa; the liquidity premium is higher for assets that are more difficult to sell during market downturns. The largest component of the estimated asset specific liquidity premium is due to the covariance between asset specific liquidity and market returns (Acharya and Pedersen, 2005). This also indicates that the difference between two asset specific liquidity premia may capture other factors than market liquidity.

Hence there are several different objections to a measure of interbank market liquidity that uses the interest differential between two bonds with (ideally) the same cash flows but different liquidity characteristics. First, it focuses on the bond market rather than the interbank market. Liquidity shocks in these two markets may in fact be highly correlated, but this is an empirical issue that remains to be studied. Second, the spread between two bond yields captures differences in asset specific liquidity rather than

\footnotetext{
${ }^{2}$ In contrast to the standard result, asset specific liquidity risk is priced in Acharya and Pedersen (2005) because they assume that all assets have to be sold each period. Also, because liquidity is stochastic, the liquid asset can be hit by a shock to the transaction cost.
} 
market liquidity. Some part of the movements in this spread may be due to market liquidity shocks, but how much is unclear and the empirical findings of Acharya and Pedersen (2005) imply that the bulk of an asset specific liquidity premium is due to the covariance between the asset specific liquidity shocks and market returns. Third, the yield spread between two bonds concerns the equilibrium price of liquidity rather than the amount of illiquidity in the market. Finally, the bundle of bonds covered by a sovereign government often includes publicly owned companies with a non-zero probability of being sold within five years, such as SBAB in the case of Sweden. ${ }^{3}$ Hence, the premium on covered bonds may include various factors specific to such companies. To conclude, there is reason to believe that the yield spread between sovereign and covered bonds is a rather different animal from the interbank market liquidity that we would like to measure.

The most common empirical measure of liquidity in empirical finance is bid-ask spreads. For instance, a recent study by Goyenko et al. (2009) investigates how well 24 different proxies of liquidity actually capture the desired phenomenon, using bid-ask spreads as the "true" benchmark measure of liquidity against which all other proxies are evaluated. A disadvantage of using bid-ask spreads is that they include various technical transactions costs that may vary for reasons that are unrelated to true liquidity. Other frequently used measures of liquidity focus on the amount of trade, such as the rate of turnover, the traded amount, or the number of transactions.

Data on bid-ask spreads or traded volume are rarely available in the case of the interbank market because information about bilateral transactions be-

\footnotetext{
${ }^{3}$ The Swedish state has already tried to sell SBAB twice, in 2001 and 2007-8, but certain paragraphs concerning what will happen to outstanding bonds in case of a change of ownership has hampered these attempts.
} 
tween banks is typically not collected by any agency. Instead, two measures of liquidity frequently encountered in empirical studies of the interbank market are the interest rate spread between bonds with similar expected cash flows but different liquidity characteristics that is discussed above and used by e.g. Schwartz, 2010, and Valenzuela, 2010, and the estimated effects of central bank liquidity injections (as in Taylor and Williams, 2009). The idea behind the latter proxy is that the more the interbank risk premium is reduced by central banks provisions of liquidity, the larger is the liquidity premium. Liquidity provided by central banks is however not necessarily a perfect substitute for genuine market liquidity and can also have signalling effects of the opposite sign. For instance, Brunetti et al. (2011) find that unexpected liquidity provisions by ECB during the financial crisis crowded out privately supplied liquidity and increased market volatility by revealing that the central bank had new private information.

Poskitt (2011) constructs two non-standard empirical proxies for interbank market liquidity: Average bid-ask spreads as quoted by dealers, and the number of dealers active in the market, using intraday quote data from the offshore market for three month US dollar funding from the Thomson Reuters Tick History database of SIRCA. He finds significant effects of liquidity on the theoretically derived non-default (or credit) component of the LIBOR-OIS spread. ${ }^{4}$

Turning to the availability of data on interbank market transaction volume, a first observation is that the interbank market is dominated by bilateral trade and details of these transaction are rarely collected by any agency.

\footnotetext{
${ }^{4}$ Following Bank of England (2007), Poskitt calculates and deducts the theoretical default related component of the interbank market risk premium using CDS data and estimate the effects of liqudity etc on the remaning part of the risk premium.
} 
There is a European electronic platform called e-Mid, covering 15-20 percent of the Eurozone interbank market trade, from which various information is recorded. Because the share of the European interbank trade covered by e-Mid fluctuates over time and has fallen considerably since the 2007-8 financial crisis, volume data from this source is less reliable than e.g. price data. A specific bank can be assumed to pay approximately the same price on transactions using this platform as through other means, but a change in traded volume on e-Mid can be due to a change in traded volume on the EMU interbank market or to a change in the banks' choice of trading mode. For instance, Vento and Ganga (2009) argues that banks were more reluctant to use e-Mid during the financial crisis because they did not want information about their trading activities to be revealed. e-Mid data are used by Angelini et al. (2011) and Brunetti et al (2011), but neither paper studies liquidity or the volume of trade since these papers focus on the effects of bank specific factors. Vento and Ganga (2009) have e-Mid transaction data but do not use it in their empirical investigation. Michaud and Upper (2008) calculate four different proxies for liquidity using e-Mid data: the number of trades, trading volume, bid-ask spreads, and the average price impact of trades, but only report eyeball econometrics of the finding that market liquidity appears to be important to the interbank market risk premium. Heijmans et al. (2010) have a similar data set for Netherlands from a platform called Target2, but also do not use them to study the relationship between market liquidity and the interbank risk premium. The market transaction volume is a straight forward measure of market liquidity. We are not aware of previous empirical studies of the liquidity premium in the interbank market using market transaction volume data. 


\section{Data}

Typically, the interbank market risk premium is defined as the (cross bank average) interbank rate minus the expected average short money market rate as measured by the Overnight Index Swap Rate, OIS. For instance, U.S. OIS rates are calculated based on the daily federal funds rate. Unfortunately, such as financial instrument does not exist in Sweden. The instrument closest to the desired measure of expected future daily policy rates is the STINA swap, where the floating leg is the average overnight intebank rate. Following the Riksbank, the Swedish interbank risk premium is calculated as the STINA swap rate plus the spread between the shortest interbank rate and the repo rate. These data are collected from Thomson Reuters.

The credit risk of domestic banks is proxied by an equally weighted average of the credit default swap (CDS) spreads of the 4 largest Swedish banks. These data are also collected from Thomson Reuters, as are US and EURO zone interbank market risk premia defined as the average three month interbank rate minus the corresponding OIS rate. Data on the deviations from covered interest rate parity (CIP) between the EURO and the USD, and between the SEK and the EURO, are calculated using three months T-bill rates and matching three months currency futures. We also have data on the implied volatility of five major international exchange rates (not including the SEK), the Swedish stock market and the U.S. stock market. All data are daily and collected from Thompson Reuter. The sample period is January 2, 2007 to November 22, 2011, see Table 1 for details.

Two different measures of interbank market liquidity are investigated. First, following Schwartz (2010) and Valenzuela (2010), we calculate the

interest rate differential between Swedish government bonds and bonds of 
the same maturity (two years and five years) that are guaranteed or covered by the Swedish government. This measure of market liquidity is contrasted to the volume of transactions on the Swedish interbank market. The data on overnight interbank market trade are based on records of loan advances and repayments processed in the Swedish large value payment system, RIX, managed by the Swedish Riksbank.

In the RIX-system, large value payments are recorded one by one by the participants themselves. In that process the banks indicate the type of transaction that the payment originates from, e.g. if the transaction is an overnight deposit with another participant bank. The data includes all transactions registered as an overnight deposit in the RIX-system, made between two banks and with a maturity from one day to the next. Hence, the transactions contain bilaterally unsecured overnight interbank deposits between the banks members in RIX. However, to the extent that the banks' make overnight deposits in the Riksbank in addition to the transactions made to manage their own liquidity position, these are most likely not caught in the data. Indicatively, such transactions are rare. In addition, the banks also make overnight transactions in the form of repos and swaps which are not captured in the data either. Finally, not all banks are members in the RIX-system. Specifically, only a few foreign banks are members in RIX. ${ }^{5}$

\footnotetext{
${ }^{5}$ The following banks are members of RIX: Bankgirocentralen, Citibank, CLS Bank, Crédit Agricole. Danske Bank. DnB NOR Bank, EMCF, Euroclear Sweden, Fortis Bank SA/NV, Kommuninvest, Landshypotek AB, Länsförsäkringar Bank, NASDAQ OMX, Nordea Bank, Nordnet Bank, Nykredit Bank A/S, Riksbanken, Riksgälden, Royal Bank of Scotland, SBAB, SEB, Skandiabanken, Svensk Exportkredit, Svenska Handelsbanken, Swedbank AB, Ålandsbanken. Banks that are not RIX members but have some activity on the Swedish interbank market include Deutsche Bank AG, JP Morgan Chase Bank, and UBS AG.
} 
These banks instead balance their liquidity by taking overnight loans with their correspondent banks, which are members in RIX. Such transactions are captured only indirectly, as they affect the correspondent banks' net balances and thus the correspondent banks' overnight loan requirements. The sample period for the data on interbank market transaction volume is July 16, 2007 to November 11, 2010. ${ }^{6}$

Several studies have shown that the deviations from covered interest parity (CIP) are strongly correlated to the interbank market risk premium (Grifoli and Ranaldo, 2010). We include the deviations from CIP between the EURO and the USD as an exogenous control variable given the assumption that Sweden is a small country that does not affect international developments.

Table 1 shows descriptive statistics, sample periods and unit root tests for all included time series. According to the ADF unit root test, the main variables are clearly $\mathrm{I}(0)$ : Swedish and US risk premia, traded volume in the interbank market, international stock volatility, international exchange rate volatility. This is an unusual finding, but our sample period is also unusually long and covers calm periods both before and after the financial crisis. The null hypotheses of the presence of unit roots is marginally rejected for several other variables, including the EURO area risk premium and liquidity measured as the spread between sovereign and covered bonds. Given the

\footnotetext{
${ }^{6}$ The Riksbank has detailed raw data on Swedish interbank market volumes contained in one excel file for each day also after November 2010. Unfortunetaly, they have not been willing to convert this information to time series data or grant us access to the original files to update the data set. For the sample period that we have, the data on transaction volumes had already been collected manually from each excel file by Riksbank staff for a different purpose.
} 
well known low power of the ADF test to reject the null hypothesis of a unit root in small samples (as documented by Kwiatkowski et al. (1992), DeJong et al., (1992), and others), the variables are treated as I(0) in most of the empirical tests. The main specification is however estimated also using first differences of the data. The Riksbank financial crisis interventions or extraordinary lending to domestic banks displays a much high p-value than the other variables. This is not surprising since the interventions are zero for most observations, with a single peak during the financial crisis. The effect of the interventions is investigated using several different specifications including dummy variables.

Table 1: Descriptive statistics

\begin{tabular}{|c|c|c|c|c|c|c|}
\hline & Sample period & Mean & Max & Min & $\overline{\text { Std }}$ & $\overline{\mathrm{ADF}}$ \\
\hline Interbank Risk Premium, SE & $07-01-01$ to $11-12-30$ & 33.34 & 146.30 & 1.00 & 22.43 & -3.038 \\
\hline Interbank Risk Premium, US & 07-01-02 to $11-11-22$ & 49.76 & 363.88 & 4.14 & 54.01 & -2.964 \\
\hline Interbank Risk Premium, EURO & 07-01-02 to $11-11-22$ & 54.00 & 195.80 & 5.30 & 34.44 & -2.184 \\
\hline CDS Spread, SE & 07-01-01 to $11-11-21$ & 98.58 & 226.74 & 19.81 & 46.68 & -2.210 \\
\hline CDS Theoretical Premium & $07-01-01$ to $10-11-29$ & 17.67 & 61.18 & 1.01 & 12.93 & -1.826 \\
\hline Liq: Bond Spread, 2 y & 07-01-02 to $11-11-22$ & 27.37 & 95.53 & -6.55 & 23.00 & -2.296 \\
\hline Liq: Bond Spread, 5 y & $07-01-02$ to $11-11-22$ & 56.00 & 111.35 & -11.20 & 36.79 & -2.234 \\
\hline Liq: Trade Vol., SEK ${ }^{*} 10^{9}$ & $07-07-16$ to $10-12-30$ & 17.7 & 79.2 & 0.051 & 18.4 & -4.438 \\
\hline RB Interventions, SEK $^{*} 10^{9}$ & $07-01-02$ to $11-11-22$ & 48.2 & 290.1 & 0 & 60.9 & -1.352 \\
\hline Implied Stock Volatility, Int. & $07-01-02$ to $11-11-22$ & 0.237 & 2.198 & -0.224 & 0.406 & -2.990 \\
\hline Implied Stock Volatility, SE & 06-06-02 to $11-06-20$ & 25.93 & 77.92 & 11.52 & 10.36 & -2.381 \\
\hline Implied XR Volatility, int & $07-01-02$ to $11-11-22$ & 0.419 & 2.250 & -0.430 & 0.449 & -2.747 \\
\hline CIP Deviation, EURO & $07-01-01$ to $11-06-17$ & 0.331 & 1.483 & -0.737 & 0.544 & -2.081 \\
\hline
\end{tabular}

Daily data. The final column contains the Augmented Dickey Fuller unit root test, where the number of lags is chosen according to the AIC. The 5 percent critical value is -2.874 (MacKinnon, 1996).

The cross correlations between the variables are shown in Table 7 . The three interbank riskpremia for Sweden, the US, and the EURO area are 
highly correlated. Volatility measures also display correlations above 0.7 with the risk premia. Figures 1 through 5 show the variables in questions. Liquidity measures as the yield spread between sovereign and covered bonds display a similar pattern as the interbank market risk premia and the volatility measures, while the volume of trade on the interbank market falls during the financial crisis and does not recover within the sample period. The Riksbank interventions are large relative to the volume of trade between banks.

\section{Empirical results}

In order to capture the effects of domestic credit risk, liquidity risk, and central bank interventions on the Swedish interbank market risk premium, we need to control for other factors influencing the risk premium and use appropriate econometric techniques and instruments to avoid endogeneity. For instance, it is not a priori clear whether higher credit risk as measure by the CDS spread of Swedish banks result in a higher interbank market risk premium, whether a higher risk premium results in higher CDS spreads, or whether both variables simply react to the same international shocks. In case of a small open economy such as Sweden, international variables can be assumed to be exogenous. Endogeneity is obviously a problem in the case of domestic variables and the central bank interventions in particular. The Riksbank's liquidity interventions may decrease the risk premium, but it is likely that the Riksbank decides to intervene when the market risk premium is perceived to be excessively high. In addition, all these variables react to the same shocks. News, for instance information about the Greek haircut negotiations halting again, are likely to affect both credit risk, market liquid- 
ity, the Riksbank credit provisions, and the interbank market risk premium. Hence instrumental variables are used to estimate these relationships. The choice of instruments is discussed in some detail below, but the main principle is to use lagged variables. Current shocks do not affect lagged variables, and a financial market shock in $t+1$ is by definition unpredictable given the information available at $t$.

\subsection{Main findings}

Given data on the CDS spreads of domestic banks and liquidity, controlling for other variables (international risk premia and international exchange rate risk), and estimating the relationship using instrumental variables, the estimated coefficients are interpreted as the effect of domestic credit risk on the interbank market risk premium:

$$
r p_{t}^{S E}=\beta_{0}+\sum_{i=1}^{k} \beta_{i} X_{i t}+\varepsilon_{t},
$$

where $r p_{t}^{S E}$ is the Swedish interbank market risk premium and $X_{i t}$ is a set of variables includes the US and EURO area interbank market risk premia, international exchange rate risk (measured as the implicit volatility of 5 major exchange rates, and the deviations from covered interest parity, CIP, between the EURO and the US dollar), domestic credit risk, liquidity, and the Riksbank interventions. The international variables can be assumed to be unaffected by shocks to the small Swedish economy. The relationship nevertheless has to be estimated using instrumental variable techniques since international shocks affect both Swedish and international variables simultaneously.

A suitable set of instruments for estimating (1) consists of variables that are uncorrelated with the error term and sufficiently correlated with the 
$X$-variables. From theory, the realization of financial variables in period $t$ should be impossible to predict using the information available at $t-1$, lagged variables are valid instruments. Given that the residuals typically display first order autocorrelation but not higher order autocorrelation, we use lags two and above. Table 2 reports the $p$-value of the $J$-test for overidentifying restrictions and the Crabb-Donald test for instrument validity. The latter approximately a multivariate equivalent to the F-test of the first stage regression in a 2SLS in the univariate case. The Crabb-Donald test falls radically when higher lags than lag three of the variables are included. Hence the standard set of instruments in Table 2 consists of the second and third lag of all variables in the specification in question. In case of the Riksbank interventions, one and two month lags are used, since the volume of extraordinary loans to the banks is not altered on a daily basis. The effects of this variable is studied more extensively in Section 4.2. More details about the set of instruments used in each specification are provided in the footnotes of the tables.

Table 2 shows the main results. Interbank markets are highly integrated across international borders and two main determinants of the Swedish interbank market risk premium are the US and EURO zone interbank market risk premia. These two variables are highly correlated (0.89) and their relative influence varies across the specifications. In column one, only international variables are included. US and international stock volatility have been excluded since they consistently lack significant effects on the Swedish interbank market risk premium over and above the effects through US and EURO interbank market risk premia. The Swedish interbank market appears to react more than the US and EURO markets to international exchange rate factors since both international exchange rate volatility and the deviations 
from CIP between the EURO and the US are significant. This is consistent with the exchange rate being more important to a small open economy than to larger and more closed economies. In the second column of Table 2, domestic variables are added to the regression. Credit risk of Swedish banks as measured by the CDS premium, domestic liquidity measured by the yield spread between sovereign and covered bonds, and the implicit volatility of Swedish stocks are estimated with negative, insignificant coefficients. Hence these domestic variables that are available for the full sample do not appear to have independent effects on the Swedish interbank market risk premium.

Columns three and four includes the traded volume on the interbank market for the shorter sample period for which this variable is available. Traded volume in the interbank market is expected to be negatively related to the risk premium and this parameter is significant. Section 4.2 shows that this finding is reasonably robust, but also that it is possible to find specifications where the volume of trade does not have a significant negative effect on the interbank market risk premium.

The final column contains standardized coefficients, where all variables have been divided by their standard deviations. This results in coefficients of comparable sizes in the sense that the relative importance of the different variables for movements in the Swedish interbank market risk premium is captured. The relative sizes of the unstandardized variables do not capture how important the variables are, since the variables are measured in different units and have different variances. For instance, judging from the non-standardized coefficients in column two, one would conclude that the Eurozone risk premium is more important to the Swedish risk premium, because its estimated effect is larger. However, even though all riskpremia are measured in the same unit (basis points, annualized), the US risk premium 
has a much larger variance and therefore accounts for more of the variation in the Swedish risk premium. Traded volume and the amount of Riksbank lending to banks is measured in SEK, which renders an evaluation of the relative importance of the variables based on estimated coefficients that are not standardized even more hazardous. The final column shows that the US risk premium is the most important determinant of the Swedish interbank market risk premium, followed by the implicit volatility of international exchange rates, the EURO/USD deviations from CIP, the covered bonds spread (although the estimated effect is negative and insignificant), interbank market transactions volume, Swedish CDS premium and then the EURO interbank market risk premium.

During the financial crisis in 2009, many central banks attempted to alleviate the credit crunch and keep the financial markets functioning. The Riksbank initiated major interventions (lending to domestic banks) in October 2008 and phased these loans out during 2010. As discussed above, we have data set covering the daily volume of credit (loans) from the Riksbank to domestic banks. This amount peaked at 300000000000 SEK or 40 percent of GDP in July 2009. The robustness of this finding is investigated in Section 4.2. Since the unit of measurement is millions of SEK, the magnitude of the effect of the interventions on the interbank market risk premium is rather modest, around 50 basis points or 0.5 percent when the interventions peaked in July 2009. 


\subsection{Robustness of the effectiveness of the Riksbank's inter- ventions}

According to the main findings in Section c, the credit provisions by the Riksbank to domestic banks are associated with a significant reduction of the interbank market risk premium. Table 3 shows two types of robustness tests of the effects of the interventions. First, the interventions variable is defined in different ways: as a continuos variable simply measuring the amount lent to the banks each day, and as a discrete dummy variable taking the value 1.0 when a positive amount is lent to the market.

The fact that this type of interventions where the central bank provides liquidity to the interbank market has significant effects on the risk premium is often taken as evidence of a market liquidity premium. For instance, Fukuda's (2011) conclusion that the effects of market liquidity are currency specific is based on the size and significance of the effects of central bank liquidity injections.

\subsection{Comparing the two liquidity measures}

The two measures of market liquidity used in this paper are (i) relative returns to a more liquid and a less liquid bonds with (ideally) the same expected payoffs and (ii) turnover (traded volume) on the interbank market. As shown in Table 7, they have a correlation of -0.22 . The negative sign is expected since a high premium on the illiquid bond signifies a negative liquidity shock, as does low traded volume on the interbank market. This correlation is however low and insignificant. It is also clear from Table 7 that the interest rate spread between covered bond sovereign bonds displays

higher correlations with measures of credit risk (CDS spreads) and domestic 
as well as international financial market risk than the transaction volume data. The correlation coefficients range between 0.67 and 0.8 in the former case and between 0.04 and 0.4 for transaction volume data.

Tables 4 and 5 show various specifications including the two liquidity measures as more and more control variables are added. Traded volume consistently enters with the expected negative sign, but is statistically significant only in about half of the cases. The covered bond spread has negative coefficients in 3 out of 8 cases and is positive and significant in two specifications. It is also highly collinear with the other variables in the regressions as indicated by the VIF measure of collinearity. Hence liquidity as measured by traded volume in the interbank market has expected effects on the interbank market risk premium, while liquidity as measured by the spread between covered and sovereign bonds typically has estimated effects of the opposite sign. Only two coefficients in Table 5 has the expected positive significant coefficients, and these are the first two specifications with no control variables and only the EURO interbank market risk premium. The final column of Table 5 shows the results from replacing the original data on the yield spread between covered and sovereign bonds by a measure of liquidity risk which is orthogonal to credit risk as measured by CDS spreads. The results are however not affected as this orthogonal measure of liquidity still enters with a significant negative sign rather than the expected positive coefficient.

\subsection{Domestic credit risk}

As evident from Table 3, the Swedish interbank market risk premium is mainly determined by international variables. The credit risk of domestic 
banks is one of the domestic variables that could be expected to influence it, but the estimated coefficients in the main results presented in Table 3 are all negative and insignificant. This result is somewhat surprising, but not unique. Several previous studies have documented significant effects of credit risk measured as domestic bank credit default spreads on the interbank risk premium (Taylor and Williams, 2009, Fukuda 2011, ). However, Michaud and Upper (2008) find a statistically and economically insignificant coefficient on CDS spreads on interbank risk premia in a very thorough study of a cross section of banks. In addition, Angelini et al (2011) document insignificant effects of observable measures of borrower banks' creditworthiness.

When the robustness exercise above is repeated for this variable the CDS premium actually has a positive significant effect on the interbank risk premium in several specification with only few control variables. These results are shown in Table 6 . In columns one to three, the only included control variables are international interbank risk premia. This results in positive significant estimates of the effect of domestic credit risk. Significance is then lost as more variables are included in columns four and five. Adding Swedish variables but excluding liquidity measured as the spread between covered and sovereign bonds still yields positive estimated coefficients. The final column shows that including this spread yields a negative coefficient. Throughout the rest of the paper, a total of twelve specifications with full sets of control variables yield negative estimated coefficients on the CDS spread in six cases and the expected positive significant coefficient only in one single case.

Given that the CDS spread itself is theoretically expected to have a non-linear effect on the interbank market risk premium while the estimated 
model is linear, we also calculate the theoretical credit premium from CDS data (following Bank of England, 2007). This transformed variable should have a linear relationship to the interbank market risk premium. As shown in column four, this measure of credit risk still enters with a negative and insignificant coefficient. Hence there is little evidence that the credit risk of domestic banks affect the Swedish interbank market risk premium once other variables are included.

\section{Conclusions}

Analyzing the interbank market risk premium is important for several reasons. The recent surge in attention is mainly due to the exploding risk premium on the interbank market during the financial crisis, as the resulting wedge between policy rates and the interest rates paid by consumers and investors hampered the expansionary stance of monetary policy. Many central banks tried to lower the interbank market risk premium using various forms of liquidity provision. The efficacy of such measure depends (among other things) on the extent to which movements in the interbank market risk premium are driven by illiquidity. There is a sizable but inconclusive literature on the relative importance of credit risk versus liquidity risk in the determination of interbank market risk premia. Different studies use different methods for separating the effects of liquidity from the effects of credit risk. Bank of England (2007) and Poskitt (2011) use credit default spreads as proxy for the credit risk component of the risk premium. Other studies estimate the effects of liquidity and/or credit risk using various proxies to identify these two components. Finding relevant proxies for interbank market liquidity is however difficult. The most common measure is the 
interest rate spread between similar bonds with different liquidity characteristics. This actually captures the difference between two asset specific liquidity premia, which according to the liquidity augmented consumption capital asset pricing model of Acharya and Pedersen (2005) is a function of the covariance between asset specific liquidity shocks and market returns.

In this paper we use actual interbank market transaction volume data collected by the Riksbank to measure interbank market liquidity. We find that the transaction volume has a reasonably robust negative effect on the interbank market risk premium. In contrast, the estimated effects of the interest differential between similar bonds with different liquidity characteristics are negative in most specifications, implying that a higher liquidity premium on covered bonds relative to sovereign bonds is associated with a lower risk premium.

Domestic credit risk as measured by the credit default spread of domestic bank does not have a significant effect on the interbank market risk premium in the benchmark specifications (this result is however not fully robust). Instead, the main determinants of the Swedish interbank market risk premium are international variables. Using standardized coefficients, it turns out that the US interbank risk premium is the single most influential factor. Furthermore, international exchange rate risk measured as the implicit volatility of major exchange rates has a large influence over and above the effects through the interbank market risk premia in the major countries. Hence the small open Swedish economy appears to be more sensitive to exchange rate risk or the factors determining exchange rate risk than the larger and less open US and EURO zone economies. The sample period includes the international financial crisis of 2008-2009 and the European debt crisis in 2011, when the domestic shocks generated by the 
Swedish economy or Swedish financial markets were relatively minor. Hence domestic factors could well have a larger influence during periods with more domestic disturbances.

Finally we study the efficacy of the Riksbank's interventions in the interbank market. Using data on the amount of credit provided to Swedish banks during the financial crisis, we find that the Riksbank was able to reduce the interbank market risk premium significantly. The effect of liquidity provided by the Riksbank does not differ significantly in magnitude from the effect of "genuine" market liquidity measured as increased transactions between banks. Finding relevant and valid instruments for the interventions is obviously troublesome. We use very long lags to instrument for the level of the Riksbank interventions. The endogeneity bias would generate a positive coefficient rather than the documented negative effect here, given that the Riksbank intervenes in times when the interbank market risk premium is high. The maximum effect of the Riksbank interventions in July 2009 is estimated to between 50 and 72 basis points or 0.5 to 0.72 percentage points.

It hence appears that a considerable part of the interbank market risk premium is due to variations in market liquidity. Furthermore, central bank liquidity provisions have a significant but rather small effect on the risk premium.

\section{References}

Amihud, Y. and Mendelson, H., (1980), "Dealership Market: Market-Making with Inventory", Journal of Financial Economics 8, 31-53.

Angelini et al. (2011),"The interbank market after August 2007: What has changed, and Why?", Journal of Money, Credit and Banking 43(5), 
923-958.

Acharya, V. and Pedersen, L., (2005), "Asset Pricing with Liquidity Risk", Journal of Financial Economics, 77, 375-410.

Baba, N. and Packer, F., (2009), "From Turmoil to Crisis: Dislocation in the FX Swap Market Before and After the Failure of the Lehman Brothers", BIS Working Papers 285.

Bank of England, 2007. "An indicative decomposition of Libor spreads", in Markets and operations, Quarterly Bulletin, 490-510.

Brunetti, C., Filippo, M., and Harris, J., (2011), "Effects of Central Bank intervention on the interbank market during the Subprime crisis", The Review of Financial Studies 24(6), 2053-2083.

Constantinides, G., (1986), "Capital market equilibrium with transaction costs," Journal of Political Economy 94(4), 842-862.

DeJong, D, Nankervis, J., Savin, N. E. and Whiteman, C, (1992), "Integration versus trend stationarity in time series", Econometrica 60(2), 423433.

Dubecq, S., Monfort, A., Renne, J., and Rousellett, G., (2013), "Credit and Liquidity in Interbank Rates: a Quadratic Approach", Bank de France Working Paper no 446.

Duffie, D., Garleanu, N. and Pedersen, L., (2005), "Over-the-Counter Markets", Econometrica 73(6), 1815-1847.

Duffie, D., Garleanu, N. and Pedersen, L.,(2007), "Valuation in Overthe-Countermarkets", The Review of Financial Studies 20(5), 1865-1900.

Fukuda, S., (2011), "Market-specific and currency-specific risk during the global financial crisis: Evidence from the interbank markets in Tokyo and London", NBER Working Paper 16962.

Glosten, L., and Milgrom, P., (1985), "Bid, Ask, and Transaction Prices 
in a Specialist Market with Heterogenously Informed Traders", Journal of Financial Economics 14, 71-100.

Goyenko, R., Holden, C., and Trzinka, C., (2009), "Do liquidity measures measure liquidity?"Journal of Financial Economics 92, 153-181.

Grifoli, T., and Ranaldo, A., (2010), "Limits to Arbitrage During the Crisis: Funding Liquidity Constraints and Covered Interest Parity", Swiss National Bank Working Papers 2010-14.

Heaton J., and Lucas, D, (1996)"Evaluating the effects of incomplete markets on risk sharing and asset Pricing.", Journal of Political Economy 104(3), 443-487.

Heijmans, R., Heuver, R., and Walraven, D., (2010), "Monitoring the unsecured interbank money market using TARGET2 data", DNB Working Paper 276 .

Korajczyk, R., and Sadka, R., (2008), "Pricing the commonality across alternative measures of liquidity", Journal of Financial Economics 87(1), $45-72$.

Kyle, A., 1985, \Continuous Auctions and Insider Trading," Econometrica, 53, 1315-1335.

Kwiatkowski, D, Phillips, P., Schmidt, P., and Shin, Y., (1992), "Testing the null hypothesis of stationarity against the alternative of a unit root: How sure are we that economic time series have a unit root?", Journal of Econometrics 54, 159-178.

Michaud, F. and Upper, C., (2008), "What drives interbank rates? Evidence from the Libor panel", BIS Quarterly Review, 47-58.

Poskitt, R., (2011), "Do liquidity or credit effects explain the behavior of the LIBOR-OIS spread?", Mimeo

Schwartz, K., (2010), "Mind the Gap: Disentangling Credit and Liquid- 
ity in Risk Spreads", University of Pennsylvania Wharton School of Business, Working Paper.

Taylor, J., and Williams, J., (2009) "A Black Swan in the Money Market", American Economic Journal: Macroeconomics, 1(1): 58-83.

Valenzuela, P., (2010), "Rollover Risk and Corporate Bond Spreads", Mimeo.

Vayanos, D., and Wang, T., (2007), "Search and endogenous concentration of liquidity in asset markets", Journal of economic theory 136(1), 66-104.

Vayanos, D., and Weill, P., 2008. "A Search-Based Theory of the Onthe-Run Phenomenon," Journal of Finance, American Finance Association 63, 1361-1398.

Vento, G., and Ganga, P., (2009), "Interbank market and liquidity distribution during the Great Financial Crisis: The e-Mid Case", Journal of Money, Investment and Banking 18, 68-94. 
Table 2: Main results

\begin{tabular}{lccccc}
\hline \hline International Variables & $(1)$ & $(2)$ & $(3)$ & $(4)$ Std & $(5)$ \\
\hline Constant & 7.573 & 29.284 & 12.432 & 0.476 & 13.888 \\
& 3.978 & $(5.792)$ & $(4.180$ & $(3.508)$ & 3.136 \\
RP US & -0.038 & 0.214 & 0.107 & 0.229 & -0.0484 \\
& -0.941 & $(4.452)$ & $(3.872$ & $(3.428)$ & -0.568 \\
RP EURO & 0.479 & 0.232 & 0.346 & 0.015 & 0.494 \\
& 5.920 & $(2.954)$ & $(5.437$ & $(5.195)$ & 3.339 \\
Impl. Vol. Int. FX & 6.518 & 18.011 & 13.685 & 0.306 & 30.684 \\
& 2.724 & $(4.408)$ & $(3.161$ & $(3.288)$ & 3.284 \\
CIP Dev E & 5.502 & 6.994 & 8.179 & 0.189 & -74.971 \\
& 2.291 & $2.603)$ & $(2.996$ & $(2.920)$ & -0.115 \\
\hline Domestic Variables & & & & & \\
\hline CDS SE & & -0.021 & -0.027 & -0.017 & 0.068 \\
& & $-0.554)$ & $(-0.959$ & $(-0.269)$ & 0.728 \\
Liquidity 2 year & -0.066 & -0.203 & -0.213 & -0.287 \\
(Covered Bond Spread) & & $(-0.750)$ & $(-2.685$ & $(-2.733)$ & -1.476 \\
Volume IB & & & $-2.01 \mathrm{E}-10$ & -0.138 & \\
& & & $(-2.827$ & $(-2.386)$ & \\
Volume RB & & & & & $-1.73 \mathrm{E}-10$ \\
Impl. Vol. Stocks SE & & -0.845 & & & -2.513 \\
& & $(-3.426$ & & & \\
\hline Crabb-Donald & 627.34 & 71.34 & 22.03 & 22.06 & 20.68 \\
Prob(J-test) & 0.724 & 0.729 & 0.561 & 0.598 & 0.348 \\
\hline \# Obs & 1161 & 1119 & 710 & 710 & 914 \\
\hline \hline
\end{tabular}

The Crabb-Donald statistics is the multivariate equivalent of the (mimimum) first stage Ftest.

$\operatorname{Prob}(\mathrm{J})$ is the marginal probability of the J-test for overidentifying restrictions.

(1), (2) The instrument set includes the second and third lags of all variables in our data set that are available for the full sample period.

(3) The instrument is the same as above plus the second and third lags of traded volume in the interbank market.

(4) The instrument set is the same as in (3). All variables are normalized by their respective standard deviation.

(5) The instruments include the second lag of the variables in the regression, and the one month lag of the Riksbank intervention. 
Table 3: The effects of the Riksbank interventions: Robustness

\begin{tabular}{lcccc}
\hline \hline & $(1)$ & $(2)$ & $(3)$ & $(4)$ \\
\hline C & 10.306 & 10.600 & 14.394 & 10.170 \\
RB Dummy & 3.688 & 2.409 & 1.890 & 3.356 \\
& -13.781 & & & \\
RB Volume & -3.893 & & & \\
& & $-2.09 \mathrm{E}-10$ & $-4.45 \mathrm{E}-10$ & $-1.41 \mathrm{E}-10$ \\
RP EURO & & -2.992 & -2.253 & -2.371 \\
& 0.445 & 0.503 & 0.560 & 0.531 \\
RP US & 3.751 & 3.357 & 2.309 & 3.889 \\
& -0.196 & -0.179 & -0.113 & -0.207 \\
FX Vol Int & -2.585 & -2.001 & -0.820 & -2.190 \\
& 8.743 & 18.133 & 58.951 & 12.840 \\
CIP Dev EURO & 1.294 & 2.327 & 2.377 & 1.769 \\
& 5.401 & -7.919 & -1.786 & 6.126 \\
Liq 2y & 1.850 & -0.014 & -1.235 & 1.134 \\
& -0.021 & -0.025 & -0.670 & -0.120 \\
CDS SE & -0.243 & -0.174 & -1.466 & -1.114 \\
& 0.120 & 0.129 & 0.306 & 0.126 \\
Relevance & 2.546 & 1.310 & 1.369 & 1.791 \\
p(J-stat) & 36.41 & 4.563 & 6.339 & 7.109 \\
\# Obs & 0.505 & 0.260 & 1.318 & 7.219 \\
\hline
\end{tabular}

The Crabb-Donald statistics is the multivariate equivalent of the (mimimum) first stage Ftest.

$\operatorname{Prob}(\mathrm{J})$ is the marginal probability of the J-test for overidentifying restrictions.

(1) The instrument set includes the second and third lags of all variables in our data set that are available for the full sample period (i.e. not the trade volume).

(2) The instrument is the same as above plus lag 42 (the two months lag) of the Riksbank interventions.

(3) The instrument set is the same as in 2 but lag 3 of all variables are excluded.

(4) The instrument set is the same as in 1 plus the five and six months lags of the Riksbank interventions. 
Table 4: The effects of traded volume: Robustness

\begin{tabular}{|c|c|c|c|c|c|c|c|}
\hline & (1) & (2) & (3) & (4) & (5) & $\overline{(6)}$ & $\overline{(7)}$ \\
\hline \multirow[t]{2}{*}{$\mathrm{C}$} & 24.223 & 3.927 & 5.855 & 4.697 & 8.398 & 8.352 & 14.511 \\
\hline & 12.187 & 2.879 & 3.497 & 2.750 & 4.306 & 2.660 & 5.199 \\
\hline \multirow[t]{2}{*}{ Traded Volume } & $2.68 \mathrm{E}-10$ & $-4.96 \mathrm{E}-11$ & $-9.01 \mathrm{E}-11$ & $-3.50 \mathrm{E}-12$ & $-1.24 \mathrm{E}-10$ & $-1.22 \mathrm{E}-10$ & $-1.75 \mathrm{E}-10$ \\
\hline & 3.700 & -1.161 & -1.977 & -0.060 & -2.038 & -1.957 & -2.263 \\
\hline \multirow[t]{2}{*}{ RP EURO } & & 0.616 & 0.537 & 0.056 & 0.477 & 0.474 & 0.257 \\
\hline & & 13.359 & 11.411 & 1.791 & 7.615 & 7.503 & 3.894 \\
\hline \multirow[t]{2}{*}{ RP US } & & & 0.057 & 0.475 & 0.082 & 0.083 & 0.127 \\
\hline & & & 2.027 & 7.381 & 2.989 & 2.975 & 3.921 \\
\hline \multirow[t]{2}{*}{ FX Vol Int } & & & & 6.296 & 7.844 & 7.910 & 17.515 \\
\hline & & & & 1.770 & 1.840 & 1.858 & 5.922 \\
\hline \multirow[t]{2}{*}{ Liq $2 y$} & & & & & -0.168 & -0.165 & \\
\hline & & & & & -2.237 & -1.995 & \\
\hline \multirow[t]{2}{*}{ CDS SE } & & & & & & 0.000 & -0.126 \\
\hline & & & & & & 0.010 & -4.053 \\
\hline \multirow[t]{2}{*}{ CIP Dev E } & & & & & & & 834.970 \\
\hline & & & & & & & 3.609 \\
\hline Relevance & 123.771 & 123.346 & 95.033 & 34.685 & 22.249 & 22.260 & 19.995 \\
\hline $\mathrm{p}(\mathrm{J}$ Stat $)$ & 0.369120 & 0.543 & 0.513 & 0.570 & 0.607 & 0.532 & 0.491 \\
\hline \# Obs & 713 & 713 & 713 & 713 & 713 & 713 & 713 \\
\hline
\end{tabular}

The Crabb-Donald statistics is the multivariate equivalent of the (mimimum) first stage Ftest.

$\operatorname{Prob}(\mathrm{J})$ is the marginal probability of the J-test for overidentifying restrictions.

The instrument set includes the second and third lags of all variables in the table. 
Table 5: The effects of bond spreads: Robustness

\begin{tabular}{lcccccc}
\hline \hline & $(1)$ & $(2)$ & $(3)$ & $(4)$ & $(5)$ & ortho \\
\hline C & 7.006 & 9.749 & 3.939 & 4.543 & 2.437 & 5.209 \\
& 2.720 & 5.601 & 2.651 & 3.132 & 0.920 & 2.115 \\
Liq 2y & 0.484 & 0.118 & 0.022 & -0.123 & -0.167 & -0.108 \\
& 7.271 & 2.148 & 0.421 & -1.626 & -2.022 & -1.875 \\
RP EURO & & 0.292 & 0.598 & 0.513 & 0.516 & 0.543 \\
& & 6.212 & 11.340 & 9.850 & 9.658 & 7.511 \\
RP US & & & 0.010 & 0.0416 & 0.035 & -0.116 \\
& & & 0.341 & 1.580 & 1.310 & -2.913 \\
FX vol int & & & & 11.223 & 10.955 & 8.522 \\
& & & & 2.994 & 2.994 & 3.056 \\
CDS SE & & & & & 0.031 & -0.021 \\
& & & & & 1.056 & -0.757 \\
CIP Dev E & & & & & & 838.796 \\
& & & & & & 4.226 \\
Relevance & 1291.641 & 846.593 & 195.592 & 93.060 & 91.806 & 141.243 \\
p(J Stat) & 0.245 & 0.264 & 0.552 & 0.606 & 0.565 & 0.754 \\
\hline \# Obs & 628 & 628 & 628 & 628 & 628 & 628 \\
\hline \hline
\end{tabular}

The Crabb-Donald statistics is the multivariate equivalent of the (mimimum) first stage Ftest.

$\operatorname{Prob}(\mathrm{J})$ is the marginal probability of the J-test for overidentifying restrictions.

The instrument set includes the second and third lags of all variables in the table. 
Table 6: The effects of credit risk: Robustness

\begin{tabular}{lcccccc}
\hline \hline & $(1)$ & $(2)$ & $(3)$ & $(4)$ & $(5)$ & $(6)$ \\
\hline C & -4.395 & -1.693 & -1.363 & 0.779 & 9.037 & 5.205 \\
CDS SE & -1.801 & -0.720 & -0.554 & 0.273 & 4.175 & 2.041 \\
& 0.112 & 0.092 & 0.099 & 0.056 & & -0.007 \\
Theoretical & 4.182 & 3.219 & 3.162 & 1.764 & & -0.278 \\
Premium & & & & & -0.315 & \\
RP EURO & 0.554 & 0.467 & 0.458 & 0.407 & -2.708 & \\
& 21.678 & 8.398 & 8.103 & 5.667 & 4.656 & 11.989 \\
RP US & & 0.083 & 0.074 & 0.093 & 0.134 & -0.123 \\
& & 2.490 & 2.081 & 2.766 & 4.358 & -2.989 \\
FX Vol Int & & & 2.545 & 5.363 & 14.077 & 11.989 \\
& & & 0.637 & 1.426 & 4.270 & 3.283 \\
CIP Dev E & & & & 147.340 & 355.627 & 761.5 \\
& & & & 0.603 & 1.569 & 3.650 \\
Liq 2y & & & & & & -0.104 \\
& & & & & & -1.809 \\
Relevance & 2974.331 & 289.636 & 8.295 & 211.548 & 206.750 & 141.243 \\
J Stat & 0.616 & 0.737 & 0.687 & 0.574 & 0.290 & 0.765 \\
\hline \# Obs & 801 & 801 & 801 & 801 & 801 & 801 \\
\hline \hline
\end{tabular}

The Crabb-Donald statistics is the multivariate equivalent of the (mimimum) first stage Ftest.

$\operatorname{Prob}(\mathrm{J})$ is the marginal probability of the J-test for overidentifying restrictions.

The instrument set includes the second and third lags of all variables in this table. 


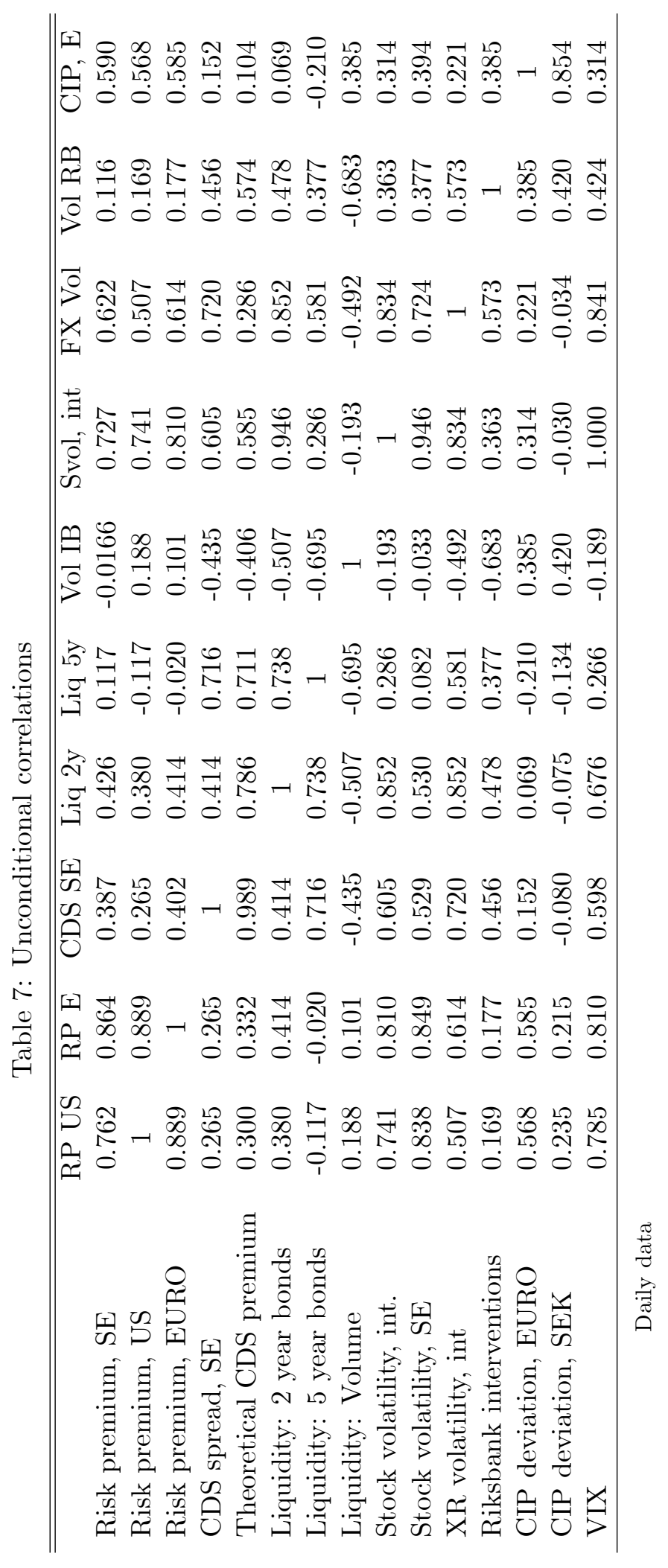

